\title{
Mobilization in Blood Bank: Mutual Assistance of "RH-"WeChat Group in New Media
}

\author{
Wei Sun ${ }^{1, a}$, Shanshan $X u^{2, b}$ \\ ${ }^{1}$ No.111, Jiulong road, Hefei city Anhui province,China \\ ${ }^{2}$ No.111, Jiulong road, Hefei city Anhui province,China \\ asunwei251@126.com, bxushanshansherry@126.com
}

\begin{abstract}
Key Words:New media mutual assistance; $\mathrm{RH}-$; Resource mobilization; Blood donation system; Abstract.By means of credibility authentication, collective memory, online to offline communication, "RH-"WeChat group could mobilize steadily the members. This paper takes "RH-"WeChat group as a case to analyze the characteristics of mutual assistance of mobilization based on the experience of blood donation by in-depth interviews.Although having absorbed western ingredients of reciprocal altruism, the mobilizationis more likely aidedbykind people. And the "panda" medal which is an annual reward also suggests that managers tend to be a traditional Chinese model of "knight-errant”.
\end{abstract}

\section{Introduction}

Academic researches view more on the way of using the Internet by groups, such as AIDS and leukemia patients, and analyze their behaviors of using media to comfort each other. Hongmei Chen analyses that the hepatitis B virus group could get a sense of belonging and a access to get social psychological support in "Gan Dan Xiang Zhao" BBS.She thinks BBS could becomeaframework for social gradual changesin reality ${ }^{[1]}$.Resource mobilization is a kind of social movement theoryrefers to the process of mobilizing people to accomplish the movement's goals.Itis a set of analysis specially whichviews social movementsas a kind of resource negotiation ${ }^{[2]}$. The key to success is assembling the resources to "bargain" with local governments or other agencies ${ }^{[3]}$. There isa significant interest demand in the movement. And it also has been taken by charity generally ${ }^{[4]}$. In 2003 after the outbreak of severe acute respiratory syndrome (SARS), a researcher analyzes the characteristics ofstrategiesin charity resources mobilization by state and society. And the mobilization host could also be members of society. Taijiang Long believes management of crisismobilization should be changed from"for social mobilization"(political mode) to "by social mobilization"(autonomous mode) ${ }^{[5]}$. And the past form of "universal mobilization" has been divided into "physical performance", "attachment return" and "independent participation" ${ }^{[6] "}$ "

Youde Zhang analyzes factors and technique strategiesof mobilizationin theprivate relief on the network by the case of "light snow ling" on TianYa BBS ${ }^{[7]}$. Compare to "RH -" group,these movements are accidental. The present situation of the lower official aid coverage and the incomplete social security system determinesordinary people are less able toenjoythe official assistancewhen disaster happened suddenly.These are such groupsknown as "panda blood” (RH -)whose blood type are rare. Inhospitals and blood stationsthereare always insufficient blood reserves when disaster strikes.It is a great threat for their life.Although blood stations will register rare blood type informationfrom blood donation, the loss of information such as phone number or address errorsare often occurred.Encountered this situation the folk starts using the new media technology to execute mutualassistance. They established "Chinese rare blood type network" and "Chinese rare blood type Union"(called union and rare shortly) which are two of the largest organizations thatboth formedcompletely a distribution over the country.The research of Ding Wei is one of the most detailed.She views the empowerment of the group practice as a gradual process, analyses the impacts of technology on individual, group and public life space under the context of Chinese ${ }^{[8]}$.This is a medium dimensionlacking of analysis for personal mutual experience in reality. So this article attempts to focus on the perspective of individual throughthe specific case and text of the new media rescue and to explore the specific characteristics of the process and further reflect on 
social problem.

\section{The studyfound}

This article mainly takesthe case of an official WeChat group of Union network in Anhui by the way of personal interviews and text analysis. The interviewee including the persons with mutual blood donation experience(they are very warm-hearted compulsory blood donors too), pregnant, group members without any experience, group managers and members joined the Union annual meeting. In addition, researchers have participatedand observed the WeChat group for two months. (As the limitation the chat text was collected by my classmates)

1. A clear division of rescue. Patients who need rare blood probably seekhelps from blood stations; however, blood reserves of stations are often insufficient. They may seek helps from related folk groups. According to their requests, the Union would contact to local group manager. Then the manager will recruit suitable donors and finally complete the donation.Before releasing the information manager must confirm the authenticity of information and usually require patients to show the relevant hospital diagnosis. Then the corresponding announcementscommonly include disease, address, gender and blood type. Volunteers who match the specific situation could offer helps."Compared with the association of blood stations information transmission of requests in Union groupis more efficient and gets responds quickly. Castle called it "a newinformation technology paradigm”, it provides the material foundation for social institutions ${ }^{[9]}$. The group, hospital, blood stationsand patients construct the complete mutual networkon the drawing of blood type and media technology.

2. The normalization and guarantee of the new media resource mobilization. Even ratio of RHis really rare (about $0.2 \% \sim 0.5 \%$ ); the amount is still huge in China. Traffic accidents, the need for surgery patients and pregnant women in labor, they all needRH- blood. There are about 5 or 6announcements in Anhui WeChat group monthly.The assistance information may come from national group and Unionwebsite, but the patients usually know localUnion network group from friends. In reality blood stations have registered the information and formed the rare blood association. Butmany people especially the elderly didn't know the rare characteristics of RHbefore they need. Asthey are not association members Union network often becomes the important daily salvage channel for them.

\section{(1).The basis of resource mobilization: credibility and common will}

Credibility always determinates successful rescue in network.”Anhui Rare Blood Type Group” which belongs to Chinese Rare Blood Type Unionis an official certificated group. As a folk organization it is,Unionestablished earlier and had a great recognition by having implemented rescues for many times successfully. And some medias have reported them. The totalnumber on its website of rescuesis 239in 2013(The publisher "little dragon" think the real number may be much more for the data loss). There ismuch news like"studentof Hainan University donates blood and is

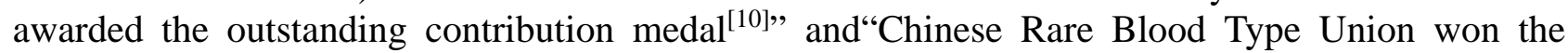

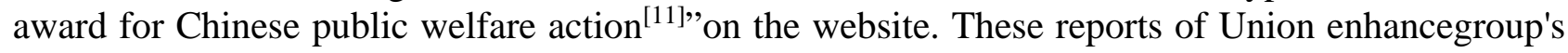
credibility and ensure themost important basis of resource mobilization.

Unlike official charities rely on government's institutional resources, folk resource mobilization is characterized by "common will”.After a certain credibility, it should form a good embedded relational network with the government and form the mobilization integrated with"embedded framework " .(Dongqiao Shi, 2009) Union's“common will” has two aspects: collective memory of group assistance and the visibility assistance of patients. As the same rare blood type owner, there is a natural bond for each other .Interviewee also said thatthere is a sense of "found the organization"when participated the group firstly. "Found the organization"and"found home”(Ding Wei, 2011) formed a similarregional identity that became the important psychological basis of "save" and "self rescue" in the group. "On distress situation, only we can help them". And the collective memory of successful salvages strengthens the emotion of memberslike the Union's slogan said“when others need help, I can stand out”.It couldbring cohesion which is the key to enhance 
members' will of donation. Mobilization is aim to help others and it is clearly justice.Volunteers know where their blood goes to and there are not any commercial elements. So,Union network oftenrecruits volunteers faster than blood stationsby mobilization.

\section{(2) Network architecture and OTO mode}

a. The network architecture. estructure of normalized mobilization is a kind of "self-organization".GuihuaYang refers to self-organization as"thing or self organizing system to realize the process of ordering behavior".It is a dynamic process ${ }^{[12]}$. The Union network's architectures also show some new characteristics. Its architecture is clearly based on the regional level. Thenumber of union network's QQ group is more than 100 in 2009.(Ding Wei,2011) And the number of official province WeChat group of Union is $20^{[13]}$. But the quantity should be much more: "there are quite a few rare blood type WeChat groups in Anhui, I have been dragged into several groups”(from interviewee). Inthe Union network's introduction, exceptlocal province groups, there arefunction groups like“national RH group manager", "relief department reception" and "kind friends". With the development of new media, Union also sets up a WeChat publicand a mobile application named "a rare blood type APP”.Especially the latter, it likes a“rescue center" andtries to make the architecture more diversified by connecting volunteers directly.

b. The OTO mode. is generally believed that WeChat like rooms in the hotel and is more suitable for friends to communicate privately. WeChat has been expanding the scope of the RH- members and also absorbing the characteristics of life.WeChat group is mixed with the information whose content involves all aspects of lifeby observing the chat logs. Members will also currently discuss the hot issues and grab a "red envelope" (it is a link that you can touch it to get the money from Publishers ) . Difference with QQ group which popularizesRH- information seriously, WeChat may turn the relationship of members from a rescuer to a friend by talking about daily life. Second, the manageralways organizes a dinner party or a holiday party to strengthen the communication between members. Anhui group hasorganized dozens of collective activities in 2015: "I also participated in several times, and we are all pretty happy in the party. The last is the Dragon Boat Festival; this activity was reported by the national group."And pictures of these activities will be shared to "circle of friends", the relationship of membershas been consolidated and strengthened by onlineto offline mode.

\section{The infiltration of business component and triple identity}

(1). penetration of business and sponsorship. e difference between Chinese union network and Chinese rare networkis whether to accept donations and to transform to commercialization. Union always insisted itself"a public platform to provide assistances for rare blood type friends, since the public welfare, it is not a for-profit, won't charge any fees."(Ding Wei,2011) For example, "D immunoglobulin"is a vaccine to prevent rare blood type pregnant women from the occurrence of hemolytic which cannot be purchased in domestic. Chinese rare networkoffers commodity for RHpregnant by acting as a purchasing agency from Hong Kong.Union network lists only how to buy a pharmacy and show the price ${ }^{[14]}$, does not involve in chasing profit. But the situation is changing. Though remaining logo "the earliest rare public welfare website and refuse to donate ", you can find information of raising money on the site in 2013 and issuing to the industry sponsorship before 2016 annual meeting. ${ }^{[15]}$ In the WeChat public, “jade lamp mountain man” donates tea cakes to sponsor ${ }^{[16]}$ the annual meeting. Union founder "little dragon"opens a WeChat-store and specially createsa group named "tea cakes booking". The responding income will be parts of funding for the annual meeting. WeChat public pushed out amessageand claimed for subscription of remainingitems after the annual meeting. Themoney will be incorporated into the Unionfund,too.

(2). the triple identity. he group manager is generally a double identity. First, he is a blood donor andwill help people who need RH- blood. Second, he is also the glue ofvolunteers and requesters in the mobilization. However, the stabilityexistence of WeChat group can bring the potential profit-making opportunities acting as a purchasing agency. In his“circle of friends”, information of purchasing agency could be found obviously.He does not directly recommendit to the members in the WeChat group; just use a "soften"way by talking about the goods to reduce dislike. Which cannot be ignored is that business practices also constitute a third identity of group manageras a 
purchasing agency. Mobilizationin the group daily needs enthusiasm; itis hard for manager to maintain enthusiasm and a good care quality in a long time. In a sense,gleaming business behaviors also help maintain stable operation of the group.

\section{The research conclusion}

1. The contradiction between rescue and chat. Chat will help promote the relations among group members in some ways. In fact, speeches are always a minority who has been met before and the rest of the "silent majority"is not enthusiastic. Too much content issue from life talking has nothing to do with the rescue and tends to bury rescue information.It is possible to delay the timing of the rescueif members set up a "don't disturb"function. Following contents are extracted from little dragon's text: "most of our group is" group of China Rare Blood Type, look at the title; it is a rare blood type group, so everyone's topic should around a rare blood type. rescue and science are two priorities ofUnion... so many content you think good are not donations are the way to make money,

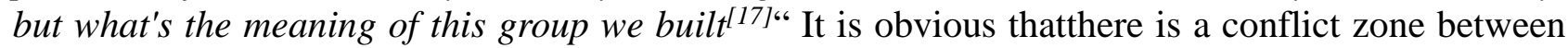
improving relationships of members and group functions. It may be difficult to reconcile them.

2. Free-rider and blood bank. There are two members in the interview and they are both graduate students. One is warm-hearted and donates blood for many times.He also donates blood by WeChat group twice and participates in the activities of group many times. Another is not enthusiastic aboutWeChat aid and does not participate in any activities. Most of the blood donators are from a minority in the statistical data in 2015. It is called "Free rider". The goal of joining the group is just in case of her blood needs when having a baby. When new members join in, he should send the mangera ritualized slogan:"when others are in trouble, I'll stand". But the effect is not well, even the active man also have hisworries:"... when I am in a difficult time, who will stand out? Because as far as I know, the emotion of blood donation in the group is not particularly enthusiastic, I joined WeChat group partly for the purpose of getting help from others."

Such worriesmay result from the "blood bank" thinking of the management. Chinese rare network originally was to build a "national rare blood type database"which is similar to "the CDMP data bank". (Ding Wei, 2011) but the latter is organizedby government andcould be transferred across the country. Union would like to form group cohesion and reciprocal mode in rare blood type group by "science and aid". The reciprocal altruism chain is a rational behavior; the prevalenceof "free rider"in the group is a kind of "speculation"yet. It is worth mentioningunion network did try to develop a "rare blood type" mobile application. It is trying to directly connect to the volunteers to integrate all mobilization links. But the effect is not well so far, users are few, there are only a few successful salvagecases. This attempt might inverselyreplace emotional components in mobilization with a tool. Secondly, the realistic sites and network groups have been established, the will of installinganother application of members is not enthusiastic. Finally, some regional assistancesare only executedby local group. It might be no needto submit to the Union again.

3. The knight-errant or chain of reciprocal altruism. Altruistic value is the goal when members donate RH- blood without any compensation. Group manager does not advocate common blood donation as they are unlikely to enjoy the securitywhen they need (revealed by interviewer). Except security, volunteers only achievecomfort of moral level."Organizations can dock the social resources and economic resources of potential through the projects and activities; it could be charity resources.” (Yonghong Long,2012) Union network meetingwas held in Beijing every past year. Members would be rewarded according to the number of blood donations. Members are issued by the numbered "union silver ${ }^{[18] \text { " }}$ in 2016. As shown in the figure below, on the front there areUnion logos and issued time. On the back there are the panda-knight designs, the panda is a metaphor for "panda blood" knight-errantrescue.

Medalsand slogans are both constituents of the normalized mobilization. The passion of blood donation of group members is much more enthusiasticthan ordinary peopleeven with "free rider". New media technology provides the mobilizationplatform, a few patterns of the chivalrous enthusiastically donating blood is a more common case than the chain of reciprocal altruism. 
Unionstill adopts a "shout slogan" mode; personal heroism is strong. It can also be found that Union seems to rely more on this modeto guide more members involved fromthe criteria of annual award. The reciprocal altruism relation was not been established in the original QQ age. Itwill become more difficultin the WeChat group which isfocused more on individual rights.

4. Incorporate or harvest. Put the individual disaster to rise to social assistanceby exposure of newspapers, radio, television and other media. Youde Zhang called it "traditional mode" mobilization. What traditional mediapattern focused on is the interaction between people and society and government. In the view of technical empowerment theory, in the "south China tiger photos" and "PX" network events, folk groups are generally considered to use the new media technology to mobilize to negotiate with the government. In Yongnian Zheng's opinion, interactions between state and society are not completely a zero-sum gamein the field of Internet. Both sides of the interaction are more of a "mutual transformation" process. ${ }^{[19]} \mathrm{As}$ a kind of "the institutional vulnerable groups", $\mathrm{RH}$ - group takes the characteristics of community mobilizationand is trying to encourage institutional changes. Folk organizers wishto obtain the official approval by establishing a larger type database."Ling Feng” and "Little dragon" reveal "who are founder of Union and Rare net are both desirous to be institutionalized"(Ding Wei, 2011); however,it will be embarrassed that blood stationsare also establishinga network group.Blood stations will registerrare blood type group to form the official database.Theywill contact people on record if there is a demand for RHblood.However, it is hard to be success, "blood stations registered, Wuhu blood stations contacted me twice, said someone needshelp, I hope I went to donate blood, but because my time is not match, both failed."It can be found that blood stations did not expect to incorporate Union, but establish their own network group and want to build their own leading status.But according to the text of interviewee, the emotion of members inside ismuchcolder than Union.

\section{The conclusion and deficiencies}

By means of credibility authentication, Collective memory to identity, online to offline communication, the group could mobilize the memberssteadily. Although having absorbed western ingredients of reciprocal altruism, group of the mobilization are more likely to be aided by individuals.And the "panda" medal which is an annual production also suggests that managers tend to be a traditional Chinese model of "knight-errant". But the "blood bank" thinking and "free-rider" phenomenon will affect the efficiency of resource mobilization inevitably.Due to the limitation of time and energy, this article does not observe other WeChat groups, the text of the collecting are not very well, its scientific reliability still needs to be improved.

\section{Acknowledgements}

This work was financially supported by the student's project ofAnhuiUniversityPublic Opinion Center in 2015(Y01002370).

\section{References:}

[1] Hongmei Chen. Network communication and social disadvantaged groups - "bind" case study J. Journal of university of news, 2005, 11:61-65

[2] Dongqiao Shi. Social resource mobilization research J. Journal of Shanghai Communication University (philosophy and social sciences edition), 2009, 05:18 to 24.

[3] Yonghong Long. The chain of reciprocal altruism: comparative study of charity organization resource mobilization officer people D. Nanjing university, 2012.

[4] Li Qin. Try to talk about the non-profit and non-governmental organizations and government relations J. Journal of Shandong university (philosophy and social sciences edition), 2005 
01:139-142.

[5]Taijiang.Long from "for social mobilization" to "by social mobilization" mobilization of crisis management problem J. Journal of politics and law, 2005, 11:17 to 25.

[6] Liu Wei. Charity resources mobilization and power boundary awareness: national perspective J. Journal of southeast academic, 2010, 2010:53-60.

[7] Youde Zhang, Songqing Zhou. Resource mobilization and the network of the folk assistance J. Journal of social, 2007 01: + 207 70-91.

[8] Ding Wei ,New media empowerment: theory construction and the case analysis, China's rare blood type group network self-organization, for example J. Open times, 2011,01:124-145.

[9]Castle.The rise of the network society M. Society.oxford.Beijing: social sciences academic press, 2001

[10]Information on Union website, http://www.rhunion.cn/html/xinwen/xiyouxuexing/201309

[11]Information on Union website,http://www.rhunion.cn/html/xinwen/xiyouxuexing/201411

[12]GuihuaYang.The organization and community self-organizing mechanism J. Journal of southeast academic.5, 2007. Pp. 122-117

[13]Information on Union WeChat public, http://mp.weixin.qq.com/s?_biz=MzA3NDI4MzNA

[14]Information on Union website,http://www.rhunion.cn/html/muyingpindao/kt/201106/28-854.

[15]Information on Union website,http:/www.rhunion.cn/html/xinwen/xiyouxuexing/

[16]Information on Union WeChat public, http://www.rhunion.cn/html/xinwen/xiyouxuexing/

[17]Information on Union WeChat public, http://mp.weixin.qq.com/s?_biz=MzA3NDI4MTNA

[18]Information on Union WeChat public, http://mp.weixin.qq.com/s?_biz=MzA3NDI4MTQA

[19] Yongnian Zheng. Empowerment, Chinese Internet technology, state and society M. Daolong Qiuinterpreted. Orient press, 2014-04 